\title{
Abundance, Excess, Waste
}

\section{Rox De Luca, Sydney-based Artist}

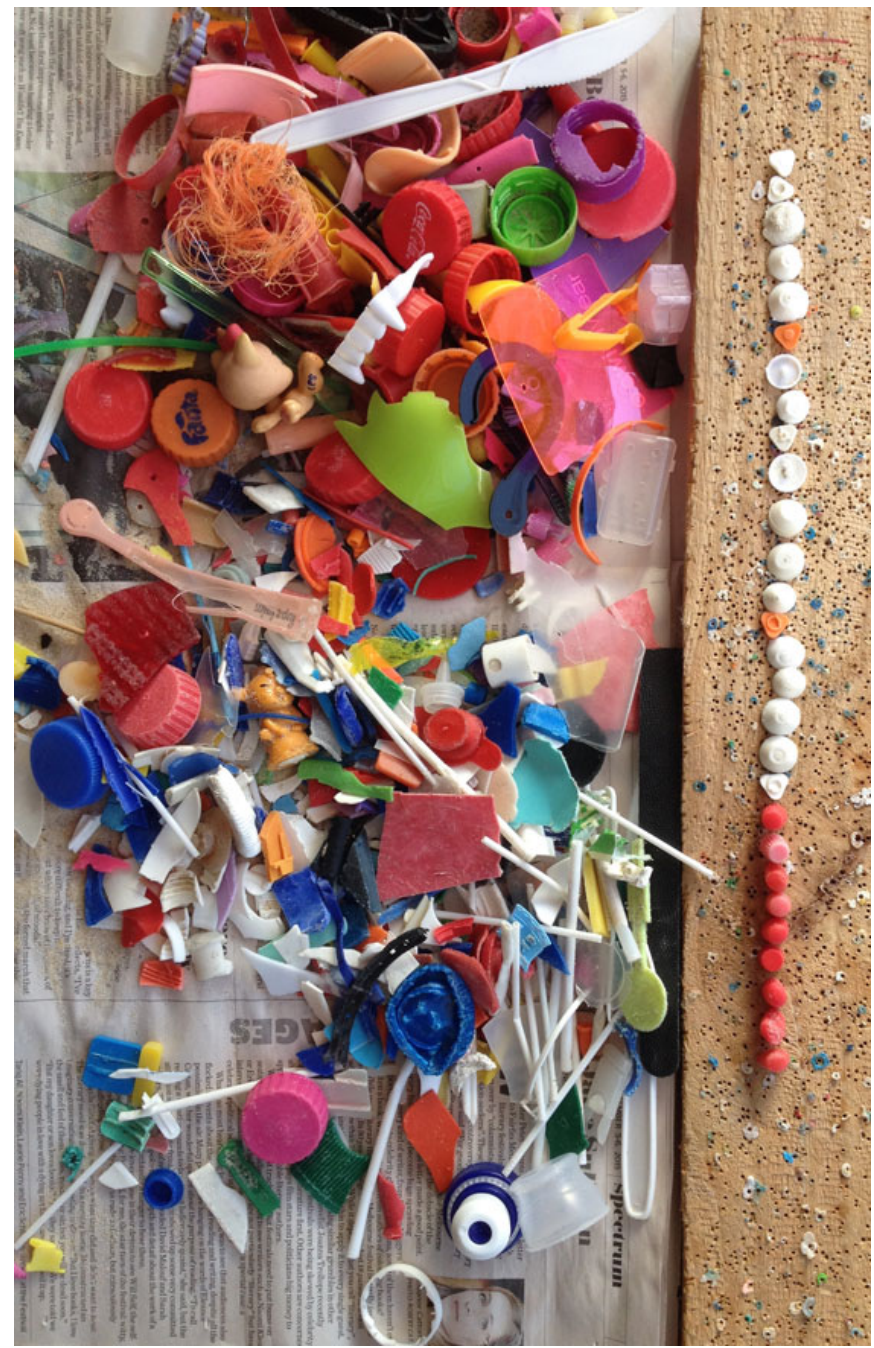

Figure 1: Miscellaneous found plastics, 2015 (C) Rox De Luca.

PORTAL Journal of Multidisciplinary International Studies, vol. 13, no. 1, January 2016.

The Transcultural Edge, curated by Ilaria Vanni Accarigi.

(C) 2016 [Rox De Luca]. http://dx.doi.org/10.5130/portal.v13i1.4793.

This is an Open Access article distributed under the terms of the Creative Commons Attribution 4.0 Unported (CC BY 4.0) License (https://creativecommons.org/licenses/by/4.0/), allowing third parties to copy and redistribute the material in any medium or format and to remix, transform, and build upon the material for any purpose, even commercially, provided the original work is properly cited and states its license.

PORTAL is published under the auspices of UTSePress, Sydney, Australia.

ISSN: 1449-2490; http://epress.lib.uts.edu.au/ojs/index.php/portal. 
My work since the early 2010s has focused on the concepts of abundance, excess and waste. These concerns have translated directly into vibrant and colourful garlands I have constructed from discarded plastics collected on Bondi Beach, Sydney, where I live.

The process of collecting is fastidious, as is the process of sorting and grading the plastics by colour and size. This initial gathering and sorting process is followed by threading the components onto strings of wire. When completed, these assemblages stand in stark contrast to the ease of disposability associated with the materials that arrive on the shoreline, evidence of our collective human neglect and destruction of the environment around us.

The contrast is heightened by the fact that the constructed garlands embody the paradoxical beauty of our plastic waste byproducts, while also evoking the ways by which those byproducts similarly accumulate in randomly assorted patterns across the oceans and beaches of the planet.

In response to works from the exhibition 'Saved-Project Wall' at the James Dohary Project Space, Sydney, in October 2012, the critic Jacqueline Milner located this ambulatory approach to collecting and reassembling the plastic detritus of contemporary life in a long tradition of artist engagements with and fascination for found objects and their malleable capacities to signify anew:

Walking, collecting and aesthetics intersect in the practice of many artists, offering a way to engage with place and landscape that materially connects the personal with the public. Such an approach also allows an artist to tread lightly, as the artwork generally reconfigures what is already there rather than adding yet another commodity to a congested world.

There is a kind of humility to this way of working, a recognition both of the creativity inherent in the everyday, and of the value of the small gesture that can subtly, but sometimes powerfully, change one's take on things. ${ }^{1}$

More specifically, for Milner, '[De Luca's] scour[ing of] her local beach-Sydney's iconic Bondi-for plastic traces which she then assembles in long ropes using the tools of a jeweller,' is guided by formal and social parameters. That is, colour choices guide the compositional process, the brightly hued results then appearing to 'sprout' from

\footnotetext{
${ }^{1}$ Jacqueline Milner, notes to accompany the exhibition 'Saved—Project Wall,' James Dohary Project Space, Sydney, October 2012.
} 


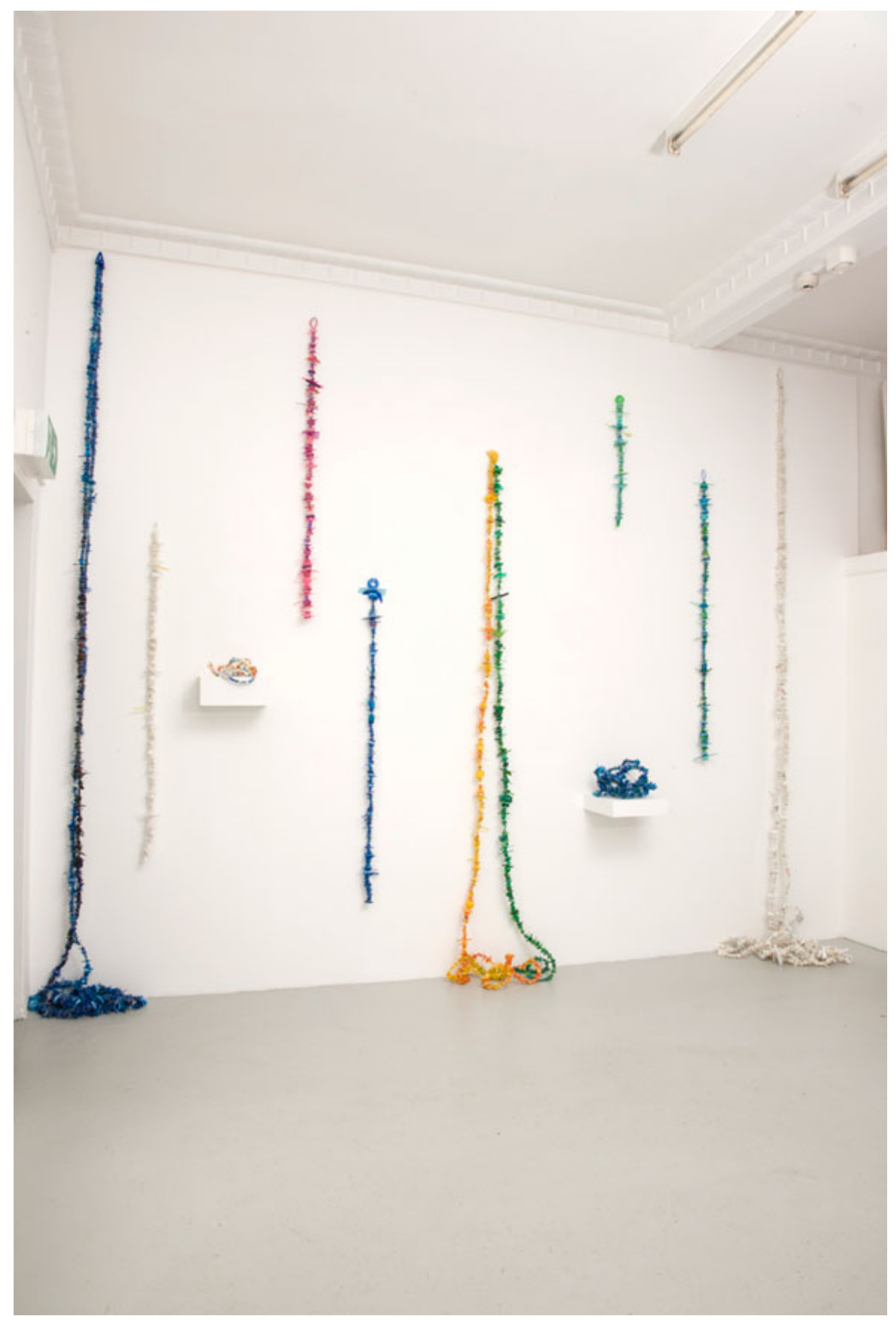

Figure 2: Installation view, Saved - Project Wall, James Dorahy Project Space, October 2012 (C) Rox De Luca. 
walls or to coil up from the floor, in installations that heighten the works' 'potential for transformation and endless accretion. Celebratory garlands (a mermaid's necklace?), or chains ready to strangle unsuspecting marine life? The works read like rosaries that count out either the pleasures of summer days or the sins of environmental neglect.'

I want my compositions to shift between the entrancingly beautiful and the grotesque; and that sensation of uneasiness is amplified when the works are placed back into the environment from which their bases in excess and waste originated.

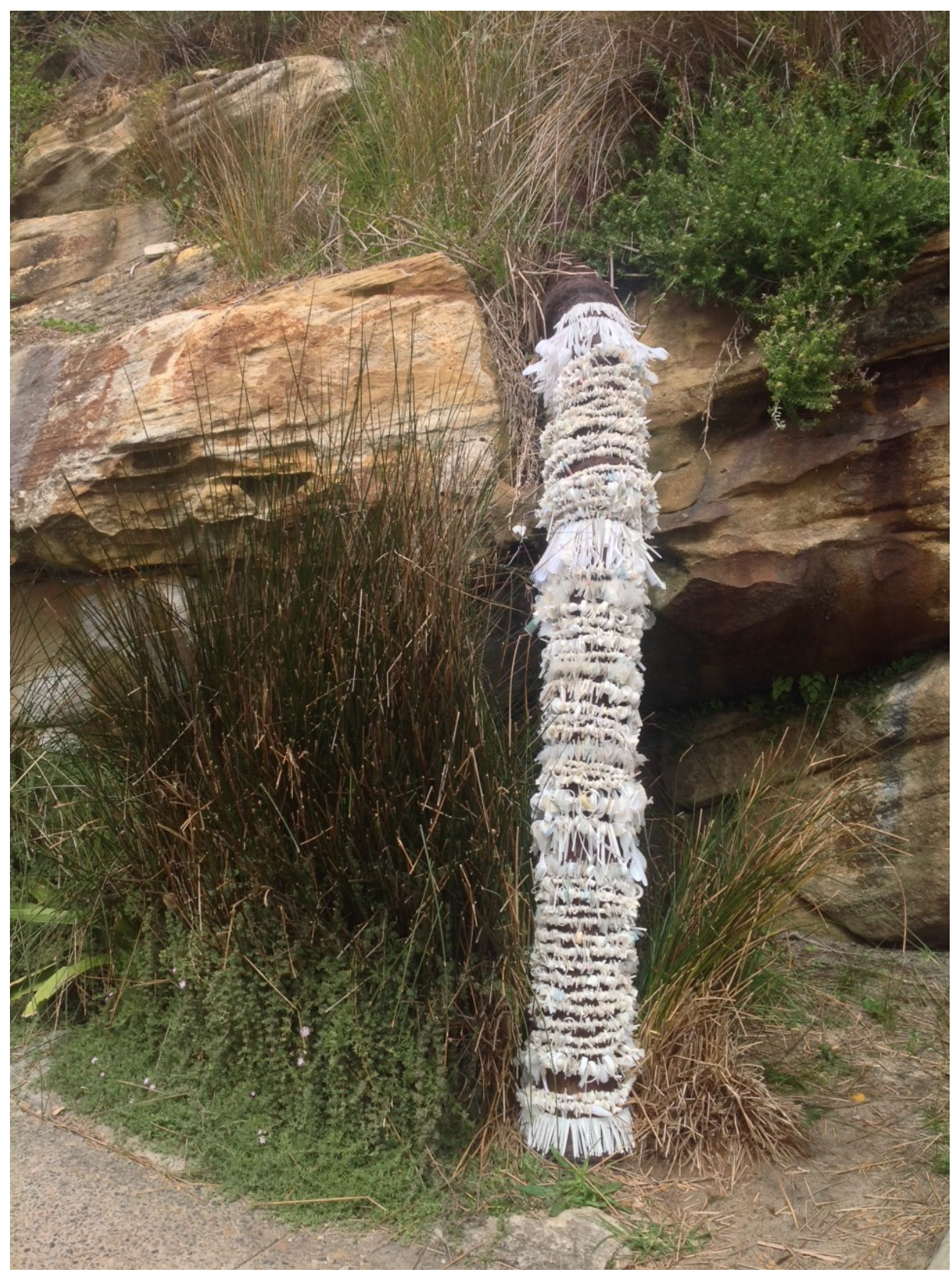

Figure 3: Saved (Rusty pipe), Exhibited: Sculpture by the Sea, 2013, site-specific sculpture Found plastics, wire, 15 metres in length $(\mathbb{C}$ Rox De Luca. 


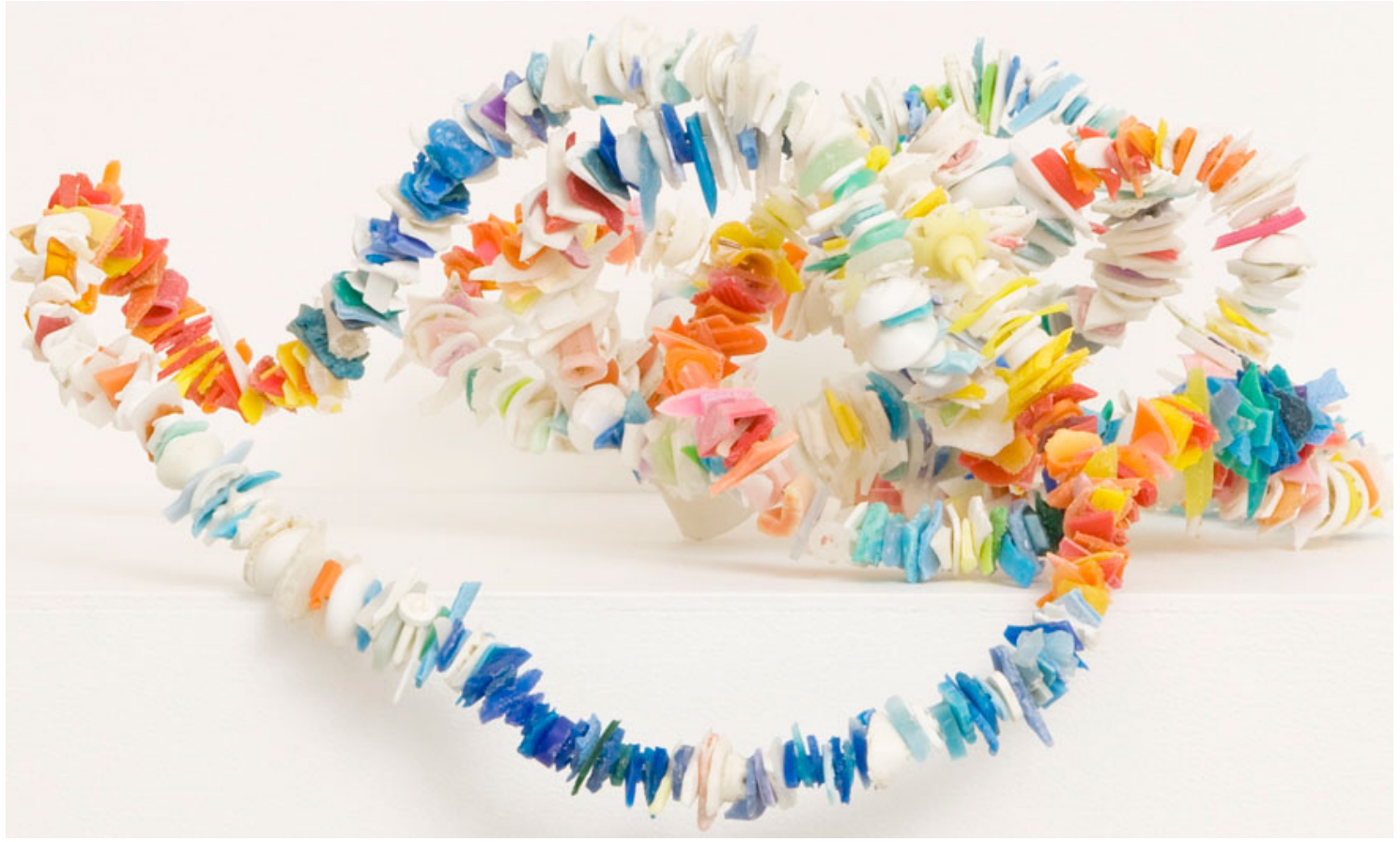

Figure 4: 'Cassata,' 2012, found plastics, 10 x 22 x 20cm. From the exhibition Saved Project Wall, James Dorahy Project Space, October 2012 C Rox De Luca.

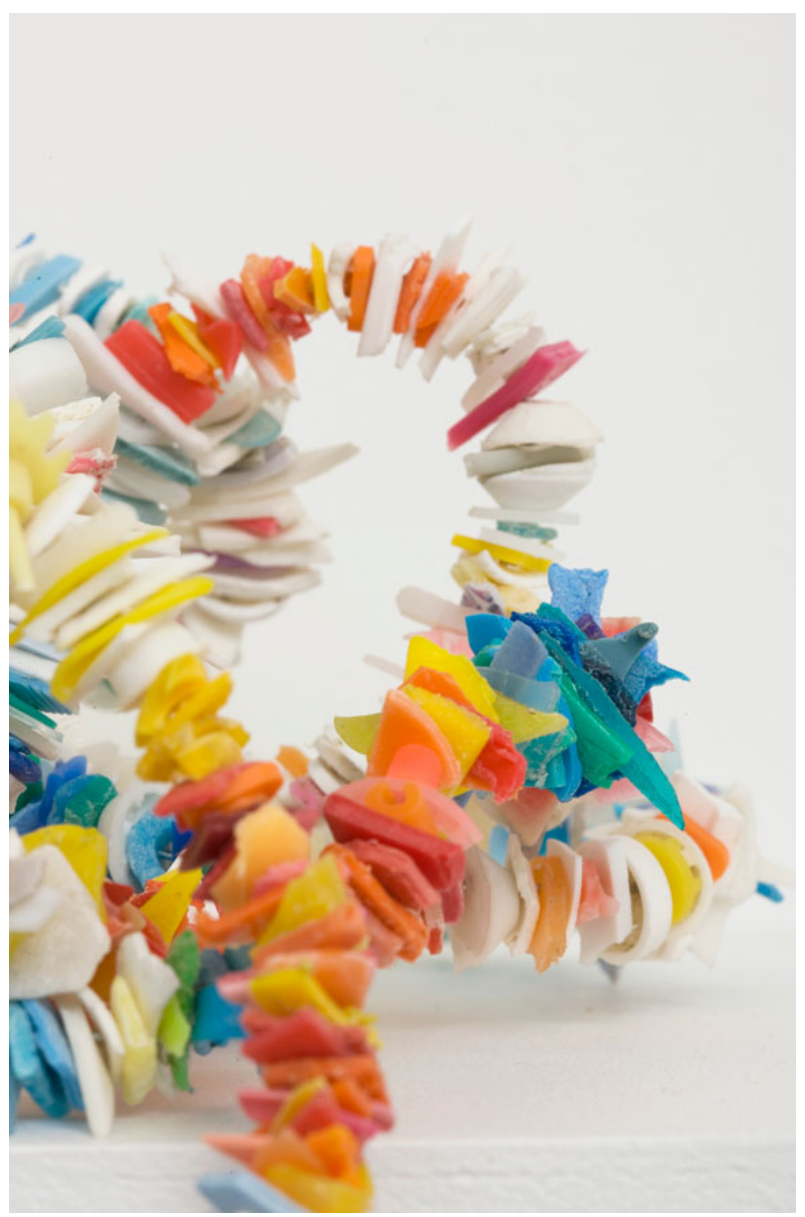

Figure 5: 'Cassata, detail.'

From the exhibition Saved Project Wall, James Dorahy Project Space, October 2012 C Rox De Luca. 


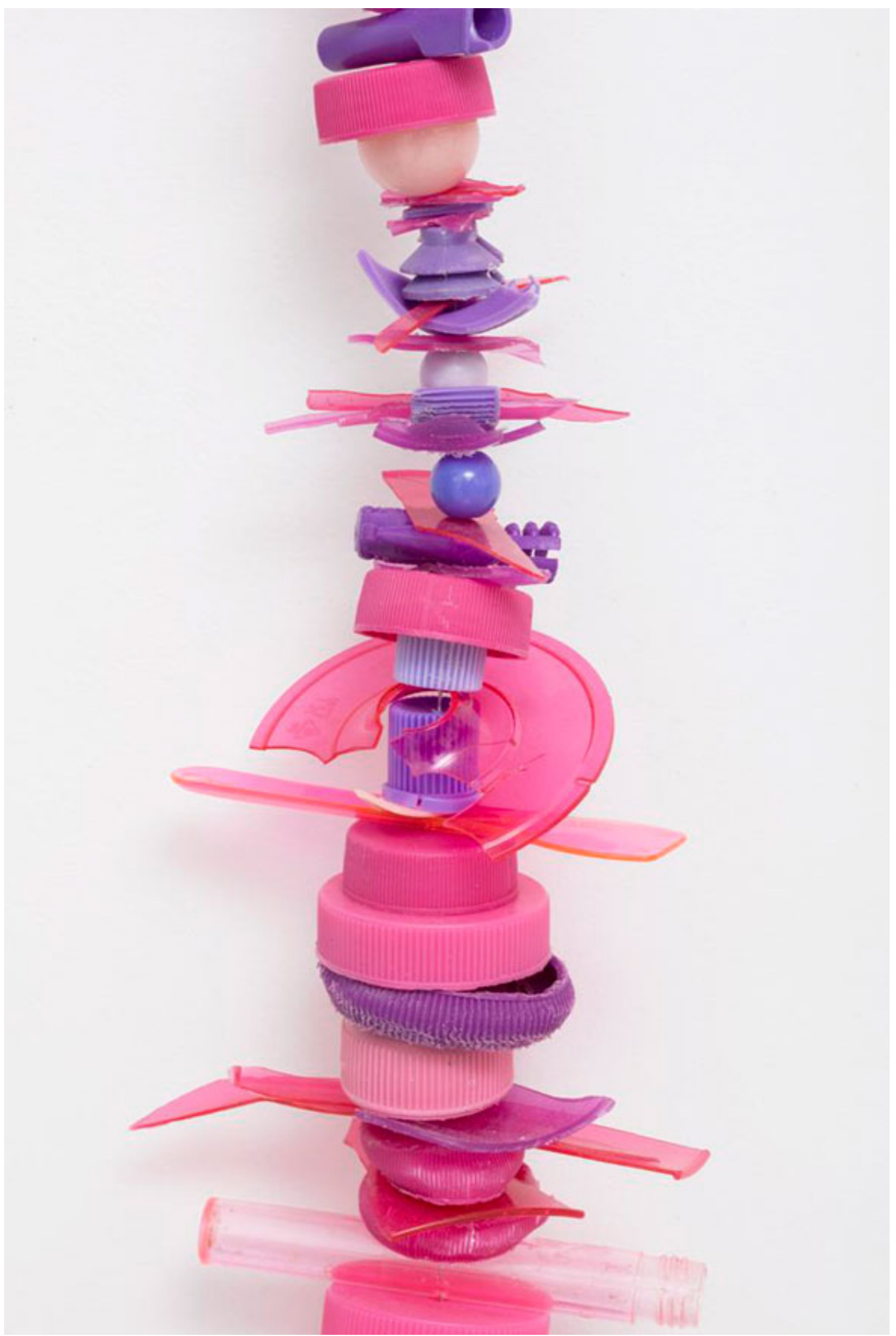

Figure 6: 'Saved (Pink\#1), detail,' October 2012 @ Rox De Luca. 


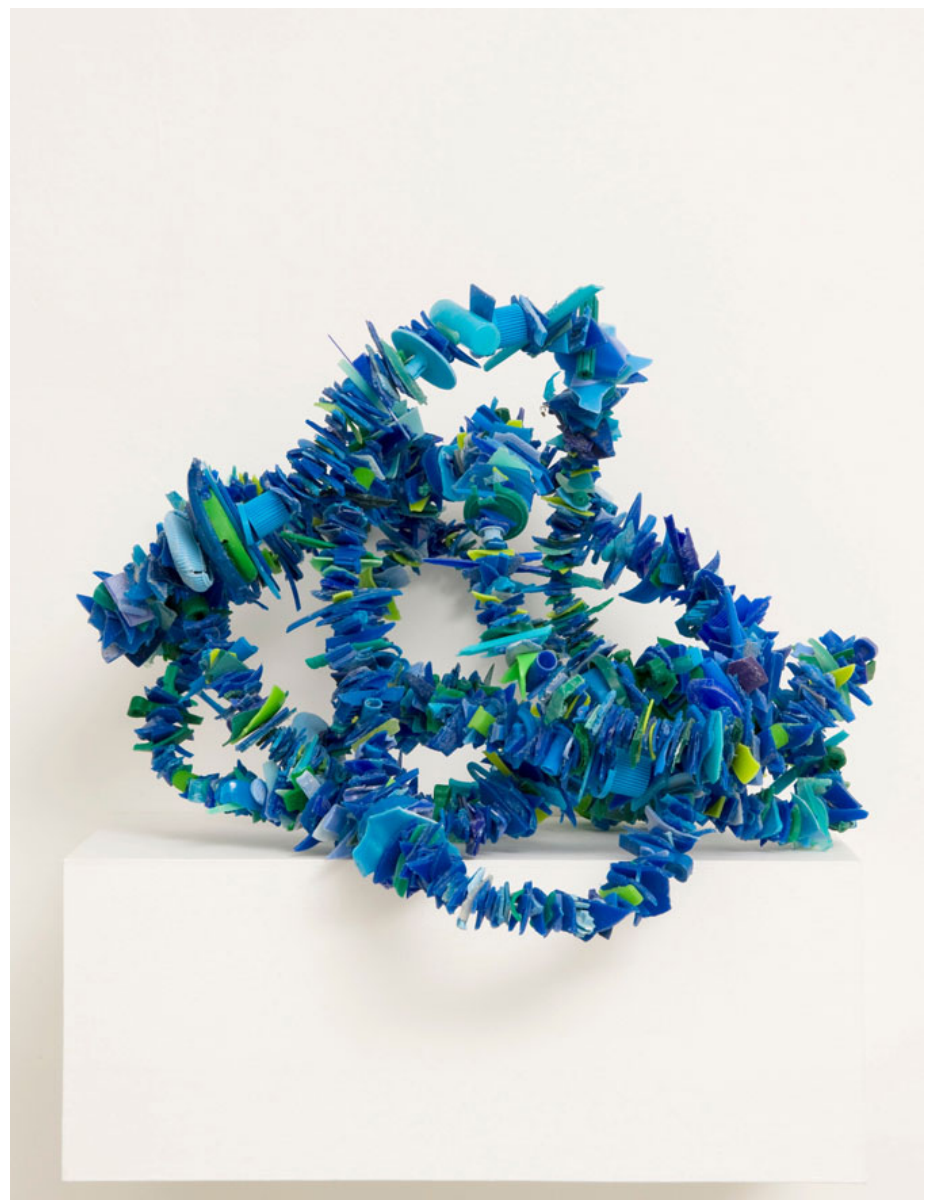

Figure 7: 'Saved (Blue) bundle,' 20 x 30 x 26cm, found plastics, wire October 2012 (C) Rox De Luca.

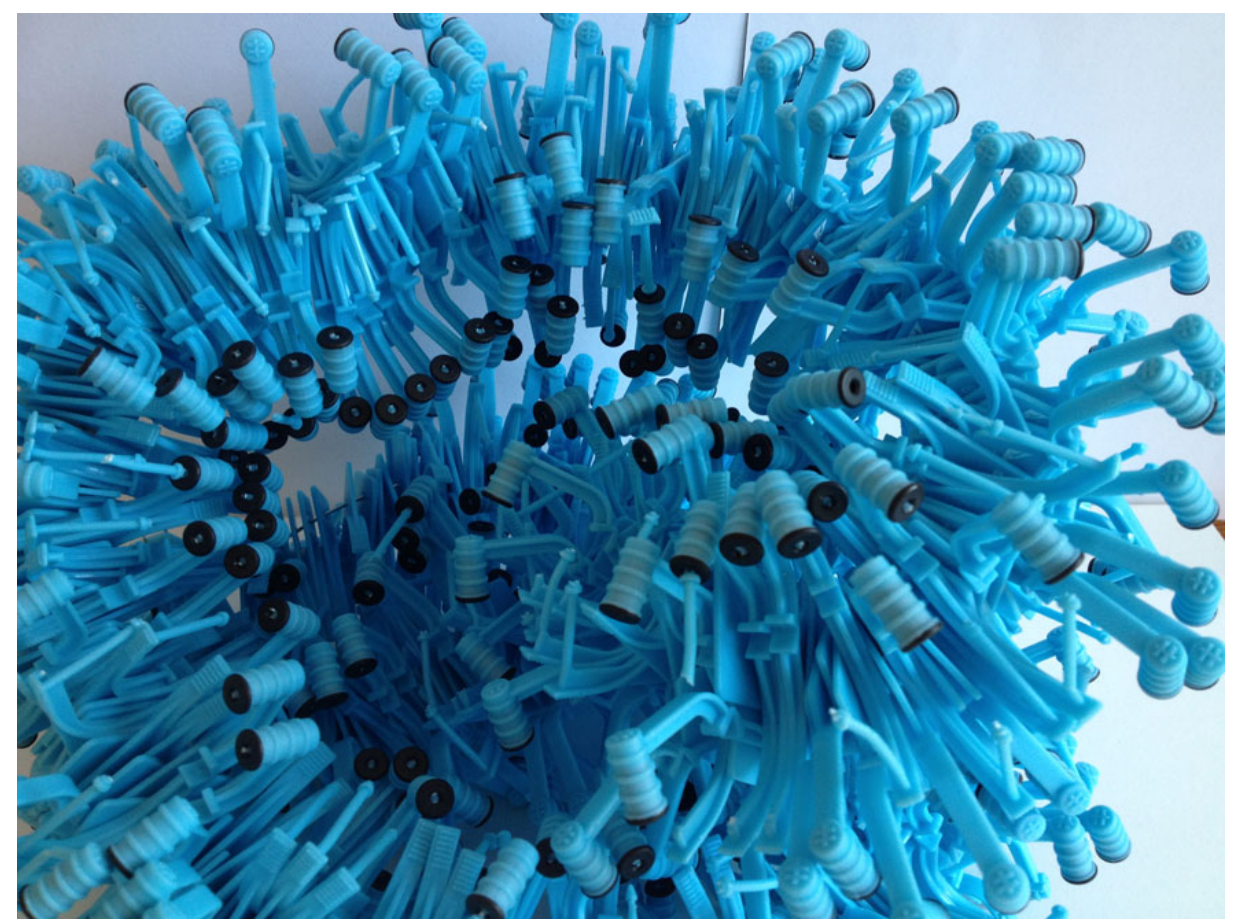

Figure 8: Saved (Blue aviation seals), detail, found plastics, 2015 C Rox De Luca. 


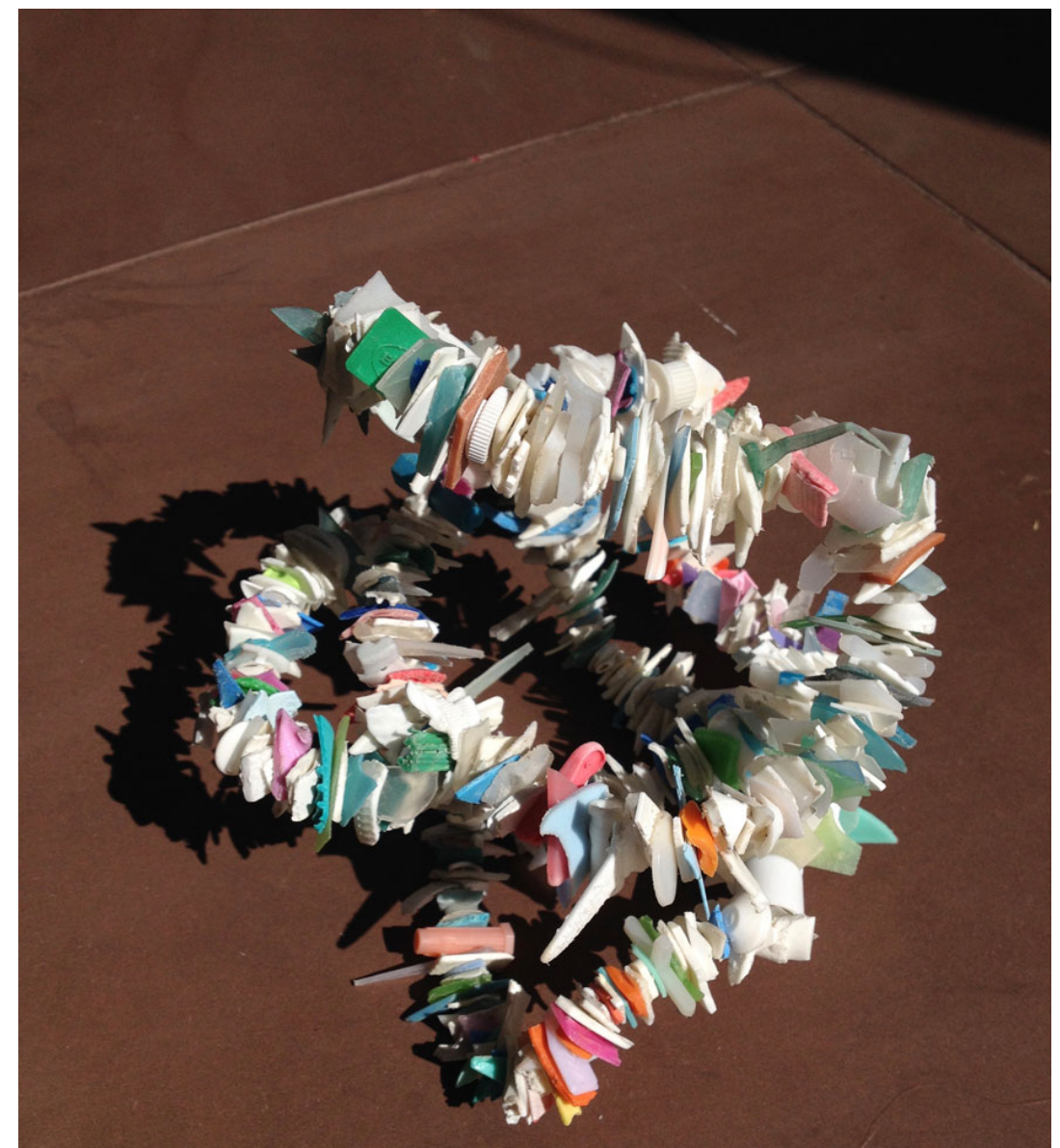

Figure 9: Cassata (for Marco), 12 x 14 x 10 cm, 2015 C Rox De Luca.

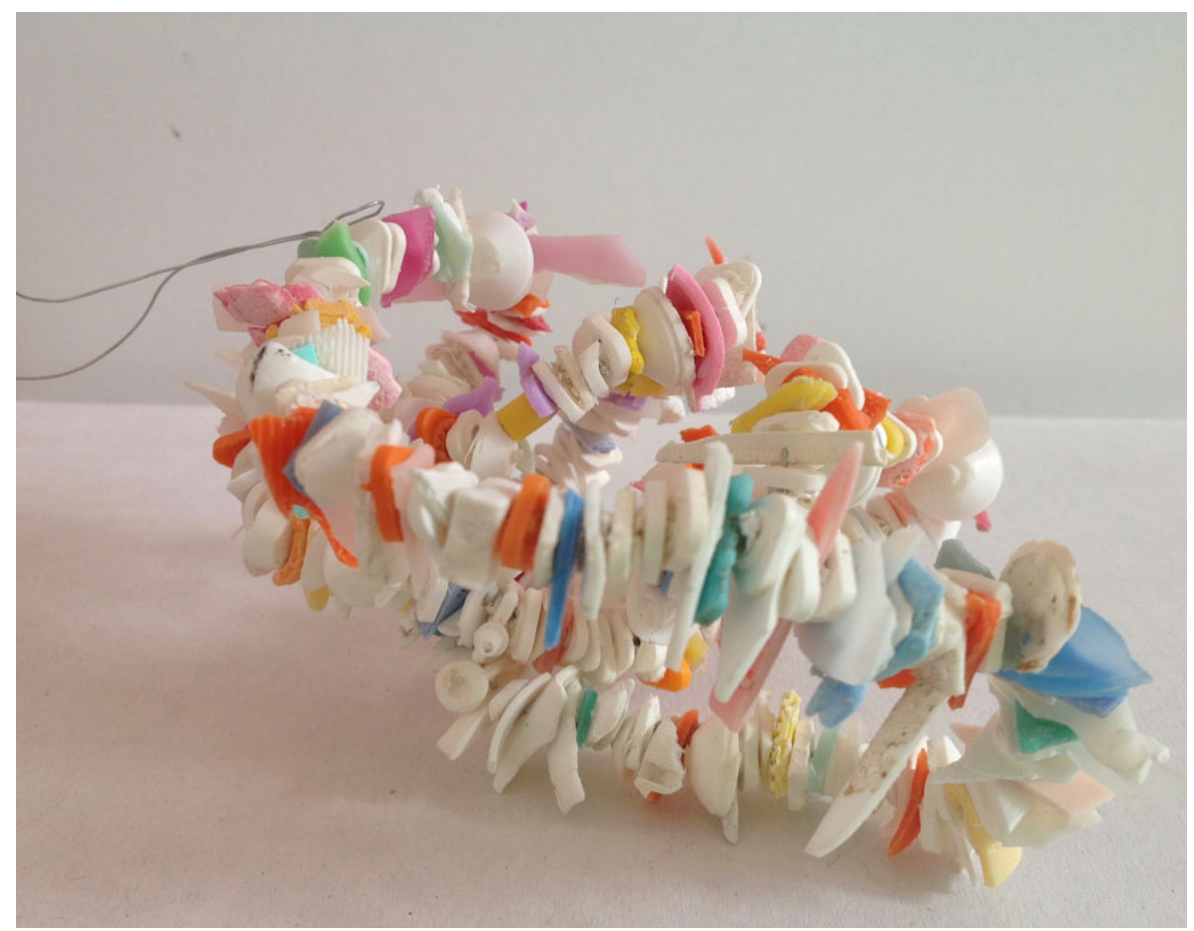

Figure 10: Saved (torrone), 2015, work in progress, found plastic and wire, $10 \times 15 \times 12 \mathrm{~cm}$, 2015 (C) Rox De Luca. 